\title{
Structure, mechanical properties and degradation behavior of electrospun PEEU fiber meshes and films
}

\author{
Wing Tai Tung ${ }^{1,2} \cdot$ Xianlei Sun $^{1,2} \cdot$ Weiwei Wang ${ }^{1} \cdot$ Xun $\mathrm{Xu}^{1} \cdot \mathrm{Nan} \mathrm{Ma}^{1,3} \cdot$ Andreas Lendlein $^{1,2,3}$
}

Received: 9 November 2020 / Accepted: 11 December 2020 / Published online: 11 March 2021

(c) The Author(s) 2021

\begin{abstract}
The capability of a degradable implant to provide mechanical support depends on its degradation behavior. Hydrolytic degradation was studied for a polyesteretherurethane (PEEU70), which consists of poly(p-dioxanone) (PPDO) and poly( $\varepsilon$ caprolactone) (PCL) segments with a weight ratio of 70:30 linked by diurethane junction units. PEEU70 samples prepared in the form of meshes with average fiber diameters of $1.5 \mu \mathrm{m}$ (mesh1.5) and $1.2 \mu \mathrm{m}$ (mesh1.2), and films were sterilized and incubated in PBS at $37{ }^{\circ} \mathrm{C}$ with 5 vol\% $\mathrm{CO}_{2}$ supply for 1 to 6 weeks. Degradation features, such as cracks or wrinkles, became apparent from week 4 for all samples. Mass loss was found to be $11 \mathrm{wt} \%, 6 \mathrm{wt} \%$, and $4 \mathrm{wt} \%$ for mesh1.2, mesh1.5, and films at week 6 . The elongation at break decreased to under $20 \%$ in two weeks for mesh1.2. In case of the other two samples, this level of degradation was achieved after 4 weeks. The weight average molecular weight of both PEEU70 mesh and film samples decreased to below $30 \mathrm{~kg} / \mathrm{mol}$ when elongation at break dropped below $20 \%$. The time period of sustained mechanical stability of PEEU70-based meshes depends on the fiber diameter and molecular weight.
\end{abstract}

\section{Introduction}

Biodegradable polymers are commonly chosen for implants in regenerative therapies to replace the damaged tissue and provide mechanical support [1]. Following the gradual degradation of the biomaterial scaffold, the development and ingrowth of neo tissue would occur.

Degradable polymers, such as poly(lactic acid), $\operatorname{poly}(\varepsilon-$ caprolactone) (PCL) and poly(p-dioxanone) (PPDO), comprise ester bonds that enable hydrolytic degradation, which can be supported by the biocatalytic activity of enzymes [2]. Co-polymers have been prepared to adjust their hydrolytic degradation rate [3]. The morphology and dimension of the material could also influence the hydrolytic degradation rate

Nan Ma

nan.ma@hzg.de

Andreas Lendlein

andreas.lendlein@hzg.de

1 Institute of Biomaterial Science and Berlin-Brandenburg Centre for Regenerative Therapies, Helmholtz-Zentrum Geesthacht, 14513 Teltow, Germany

2 Institute of Biochemistry and Biology, University of Potsdam, 14476 Potsdam, Germany

3 Institute of Chemistry and Biochemistry, FU Berlin, 14195 Berlin, Germany
[4]. Electrospun fiber meshes are widely explored as porous scaffolds in regenerative therapies [5].

The polyesteretherurethane PEEU70 is a multiblock co-polymer consisting of PPDO and PCL segments with L-lysine-based diurethane junction units. Adjustment of the segment weight ratio of PPDO and PCL can alter the co-polymer properties resulting in different biological effects [6, 7]. Another formulation of PEEU is PDC, which was prepared by linking PPDO and PCL diol with hexamethylene diisocyanate (HDI). One of the factors determining successful biomaterial-induced tissue regeneration is the vascularization of the neo tissue in the early phase after implantation [8]. A PDC film promoted angiogenesis [9] and an electrospun PDC fibrous scaffold with aligned fibers revealed a strong angiogenesis after implantation [10]. Different PPDO to PCL weight ratios of PEEU material have been tested for angiogenesis. A higher number of endothelial tubing formation could be achieved when the endothelial cells were cultured on PEEU with the weight ratio of PPDO to PCL 70:30 [7]. It was claimed that the elastic modulus of the fibrous scaffold affected the tubing formation capacity of the endothelial cells after re-seeding into normal culture wells. Past publication reported the degradation of PDC electrospun fibers with equal ratio of PPDO and PCL segments [11]. This study mainly investigated the hydrolytic degradation behavior of PEEU (PPDO 
to PCL segment weight ratio 70:30) as fiber meshes in comparison to a dense film. The polymer samples were sterilized before performing the degradation experiment and the degradation behavior was analyzed by means of gravimetric measurements, scanning electron microscopy, tensile testing, and gel permeation chromatography (Fig. 1a). (a)

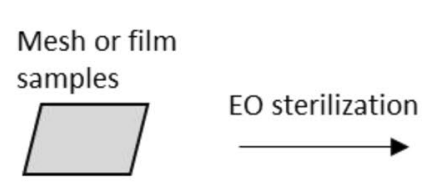

Cut in size and weighted
Incubated in PBS at $37^{\circ} \mathrm{C}, 5$ vol\% $\mathrm{CO}_{2}$

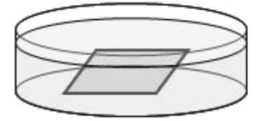

PBS changed every week
Samples collected and air-dried at time point

week 1,2, 4 \&6 Characterization:

weight change

SEM

tensile test

GPC

(b)

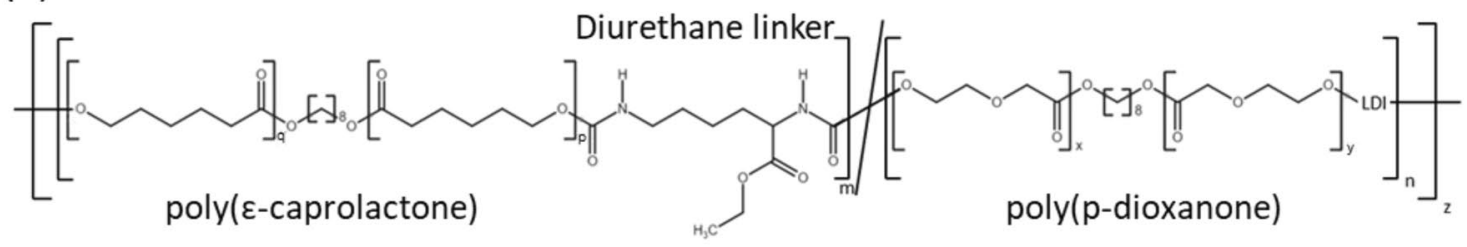

(c)

mesh1.5

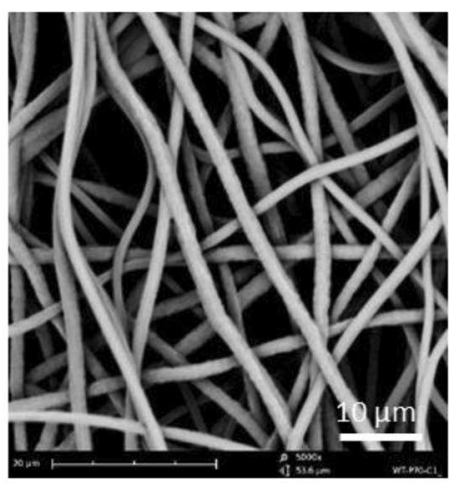

(d)

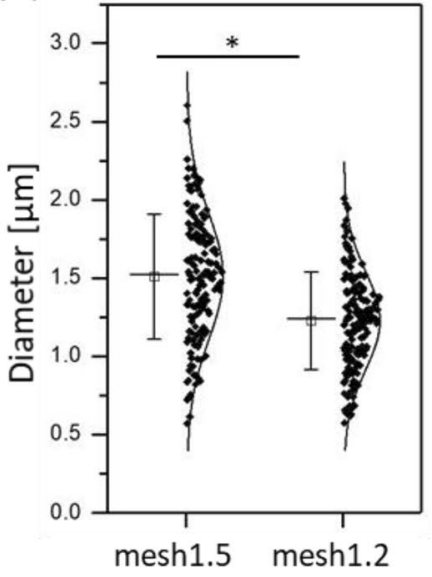

(e)
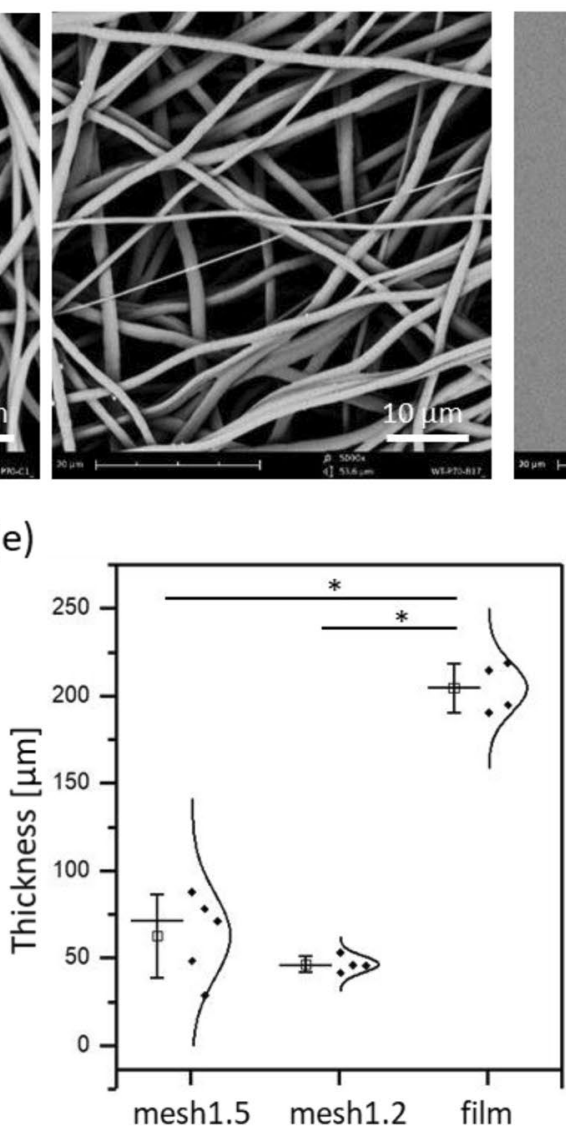

film

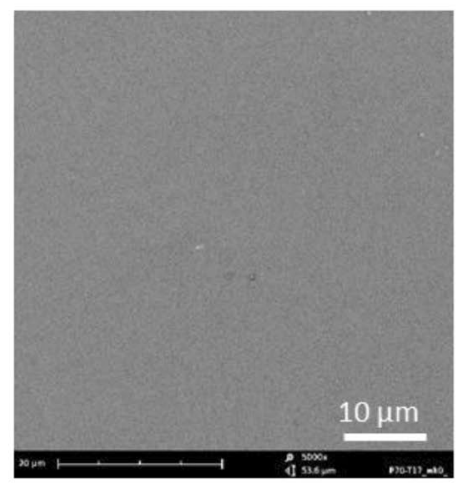

(f)

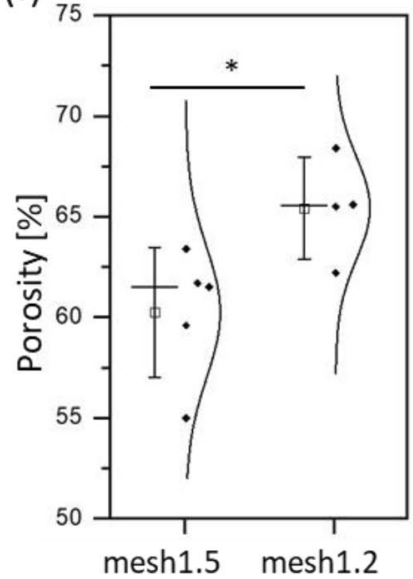

Fig. 1 Hydrolytic degradation experiment and geometry of samples used. a Schematic illustration of the experiment design. b Molecular formula of PEEU70. c SEM images showing the surface morphology of mesh1.5 with average fiber diameter of $1.5 \pm 0.4 \mu \mathrm{m}$, mesh 1.2 with average fiber diameter of $1.2 \pm 0.3 \mu \mathrm{m}$, and film before degrada- tion. $\mathbf{d}$ Plot of the fiber diameter distribution of mesh1.5 and mesh1.2 groups. $n \geq 140$ e Plot of fiber meshes and film thickness distribution included in the hydrolytic degradation. $\mathbf{f}$ Plot of the porosity of the fiber meshes. Upper and lower whisker line indicates the \pm SD and the center line is indicates the median. $\square=$ mean. $n \geq 4, * p<0.05$ 


\section{Method and materials}

\section{Chemicals and reagents}

Polyesteretherurethane (PEEU70) was obtained as described previously [11]. Hexafluoroisopropanol (HFIP) used as solvent for dissolving the polymer for electrospinning was purchased from Abcr GmbH (Germany). Phosphate-buffered saline (PBS) used as degradation medium was purchased from Sigma-Aldrich Chemie GmbH (Germany).

\section{Preparation of electrospun fibers}

The electrospinning setup (Linari Engineering, Italy) consists of a voltage supply, a rotatory drum collector, and a syringe pump. Electrospinning was performed in a homemade transparent plastic chamber with tubing connected to air source for humidity control. PEEU was dissolved in HFIP at a concentration of $11 \mathrm{wt} \%$. The PEEU70 solution was filtered with glass fiber syringe filter of $1 \mu \mathrm{m}$ pore size before electrospinning. A 19-guage blunt tip needle was connected to the tubing and syringe containing the PEEU70 solution. The flow rates of PEEU70 solution supply for electrospinning were $1.62 \mathrm{ml} / \mathrm{h}$ and $1.77 \mathrm{ml} / \mathrm{h}$. The tip to collector distance was kept at $25 \mathrm{~cm}$, with a voltage supply of $10-15 \mathrm{kV}$ and under a humidity of $20 \%$ to produce stable electrospinning, where the fibers deposited on a drum collector rotating at $5 \mathrm{rpm}$ for $4 \mathrm{~h}$.

\section{Preparation of PEEU70 films}

PEEU70 films were prepared by compression-molding. 1 $\mathrm{g}$ of PEEU70 was placed in between two metal plates with polypropylene films separating PEEU70 and both metal plates. The plates were compressed at 5 bar, heated up till $100{ }^{\circ} \mathrm{C}$ for $15 \mathrm{~min}$. Then pressure was applied to $200 \mathrm{bar}$ at $100{ }^{\circ} \mathrm{C}$ for $15 \mathrm{~min}$ followed by cooling to $25^{\circ} \mathrm{C}$ with a pressure of 200 bar.

\section{Degradation experiments}

The fiber mesh was cut into $10 \mathrm{~mm} \times 20 \mathrm{~mm}$ specimens and the films were stamped into dog bone-shaped specimens with gauge section of $2 \mathrm{~mm}$ and $20 \mathrm{~mm}$ in width and length, respectively, for tensile test measurements after collecting from degradation experiments. All specimens were weighted and packed in a sterilization bag for ethylene oxide (EO) sterilization at $45^{\circ} \mathrm{C}$ for $3 \mathrm{~h}$ at 1.7 bar before the degradation experiment. PEEU specimens were transferred from the sterilization bag to 6-well plates with each well given $1 \mathrm{ml}$ PBS in a biological safety cabinet. The 6-well plates with specimen were placed in the incubator at $37^{\circ} \mathrm{C}$ with 5 vol\% $\mathrm{CO}_{2}$ supply over a period of 6 weeks. The PBS was changed weekly. At designated time points (week 0, 1, 2, 4, and 6), specimens to be collected were washed with deionized water twice, air-dried, followed by a weighing process.

\section{Scanning electron microscopy (SEM) imaging}

The surface and morphology of fiber meshes and films were characterized by SEM (Phenom88 G2 Pro, Phenom World). The specimens placed on samples stub were first incubated in vacuum overnight and coated with $5 \mathrm{~nm}$ gold in a sputter coater (Polaron SC7640). The samples were then transferred to the sample holder of the SEM. SEM images were used to determine the fiber diameter with Image J software (NIH, USA).

\section{Mechanical characterization}

A tensile test machine with thermochamber (Zwick GmbH, Germany) was used to determine the mechanical properties of meshes and films at $37{ }^{\circ} \mathrm{C}$ in dry state. At least four randomly selected samples per group were measured. The measurements were performed at a constant speed of $5 \mathrm{~mm} /$ min until the sample underwent elongation of break. The elastic modulus was calculated from the slope at linear elastic deformation by Hooke's law.

\section{Porosity}

The porosity of the fiber mesh was calculated by the measured scaffold dimension and the actual volume from the measured sample mass and the material density. The density of PEEU70 is $1.044 \mathrm{~g} / \mathrm{cm}^{3}$.

\section{Gel permeation chromatography (GPC)}

The weight average molecular weights of PEEU70 and partially degraded polymer samples were determined by multidetector GPC measurements. GPC measurements were performed at a solvent flow rate of $1 \mathrm{ml} / \mathrm{min}$ at $35{ }^{\circ} \mathrm{C}$ using chloroform as eluent and $0.2 \mathrm{vol} \%$ toluene as internal standard. The system was equipped with a precolumn, one $300 \mathrm{~mm} \times 8.0 \mathrm{~mm}$ SDV analytical linear XL column (Polymer Standards Service GmbH, Germany), an isocratic pump PSS SECurity 1260 (Polymer Standards Service GmbH, Germany), an automatic injector AS 2050 (Jasco, Japan), a refractive index detector RI-930 (Jasco, Japan), and a viscosity detector Viscotek T-60A (Viscotek GmbH, Germany). The SEC software WINGPC UniChrom V8.33 Build 9050 (Polymer Standards Service GmbH, Mainz, Germany) was used to determine the molecular weight distributions by universal calibration with polystyrene standards from $1.82 \mathrm{KD}$ 
till 975 KD (Polymer Standards Service GmbH, Germany) using an value for inlet pressure calculated by the software Omnisec V 4.6.1354 (Malvern, UK). The error of the measurement method was estimated as $10 \%$ based on the measurements of polystyrene standards.

\section{Statistical analysis}

The number of replications for experiments was at least three. Statistical analysis was performed using two-tailed independent-samples $t$-test. $p<0.05$ was considered statistically significant. Data were reported as mean \pm standard deviation.

\section{Results and discussion}

PEEU70 is composed of poly ( $\rho$-dioxanone) (PPDO) and poly( $\varepsilon$-caprolactone) (PCL) segments with a weight ratio of 70:30 with L-lysine diisocyanate-based diurethane junction units bridging the segments (Fig. 1b) and was studied in the form of fiber meshes and films for their hydrolytic degradation in PBS. Hydrolytic degradation of PEEU70 is mainly controlled by the amount of PPDO segments due to the more hydrophilic character of PPDO domains supporting hydration and the easily cleavable ester bonds formed by glycolide units $[2,12,13]$. Previous degradation studies of similar multiblock co-polymers were performed on PDC fibers with a PPDO to PCL weight ratio of 50:50 [11] or on films with different PPDO to PCL segment weight ratios [3, $14,15]$, but with a different diurethane junction unit. In this study, the degradation behavior of PEEU70 fiber meshes prepared by different flow rates in electrospinning (mesh1.5 and mesh1.2) and a PEEU70 film was investigated for 6 weeks. This time period was selected considering a cardiac patch as potential application, where a successful regeneration within 4 weeks has been reported elsewhere [16].

The surface morphology of PEEU70 samples was examined through SEM and the fiber diameters were measured from SEM images by Image J (Fig. 1c) before the degradation ( $\mathrm{n}>140$ fibers were measured). The two different flow rates, $1.77 \mathrm{ml} / \mathrm{h}$ and $1.62 \mathrm{ml} / \mathrm{h}$, resulted in two different average fiber diameters of mesh samples, $1.5 \pm 0.4 \mu \mathrm{m}$ and $1.2 \pm 0.3 \mu \mathrm{m}$, for which the samples are named as mesh1.5 and mesh1.2 (Fig. 1d). The thickness of mesh1.5, mesh1.2, and films was $62.9 \pm 23.9 \mu \mathrm{m}, 46.6 \pm 4.7 \mu \mathrm{m}$, and $204.7 \pm$ $14.1 \mu \mathrm{m}$, respectively (Fig.1e) measured by thickness gauge. Porosity of mesh1.5 and mesh1.2 was determined to be 60.2 $\pm 3.2 \%$ and $65.4 \pm 2.5 \%$ (Fig. 1f).

SEM was used to examine the morphological features of the meshes and film surfaces with proceeding hydrolytic degradation. Figure 2 shows the images of PEEU70 meshes and film surfaces at the indicated time points during exposure to the PBS solution. The SEM images of the fibers from mesh 1.5 and mesh 1.2 showed obvious degradation starting from week 4 , where the cracks perpendicular to the fiber axis could be found as indicated by yellow arrows. Due to the fiber geometry and the diffusion rate of water into the polymer, the hydrolysis of PEEU70 fibers would be bulk degradation [4]. More in detail, hydrolytic degradation of PPDO was reported to proceed in two phases, where the inter-lamellar amorphous regions would be firstly attacked hydrolytically followed by the slow degradation in crystalline regions [13]. As the process of electrospinning directs the molecular orientation along the fiber axis in stackedlamellar crystal morphology [17], the cracks from hydrolytic degradation cut the fiber in between the stacked-lamellar crystal structure, which is perpendicular to the fiber axis. The fiber diameters showed little unevenness in week 4 and the degraded ends showed a clear-cut without cavity degradation on the surface, indicating that the hydrolytic degradation would be bulk degradation [4]. The cracks perpendicular to the fiber axis further increased in week 6 and the cracks distance on same fiber was decreased. For film specimens, the surface roughness had no obvious changes in the first 2 weeks. From week 4, unsmoothed surface with series of wrinkles was observed on the film, which could be corresponded to the crystalline region of the polymer film.

The weight average molecular weight $\left(M_{\mathrm{w}}\right)$ of the raw material was determined to be $264 \mathrm{~kg} / \mathrm{mol}$. Processing of this materials into meshes or films led to a decrease in $M_{\mathrm{w}}$. The $M_{\mathrm{w}}$ of mesh 1.5 was starting at $54 \mathrm{~kg} / \mathrm{mol}$ and gradually decreased to $20 \mathrm{~kg} / \mathrm{mol}$ while that of mesh1.2 was starting at $77 \mathrm{~kg} / \mathrm{mol}$ and decreased to $14 \mathrm{~kg} / \mathrm{mol}$ in week 6 (Fig 3a). The film had a $M_{\mathrm{w}}$ of $171 \mathrm{~kg} / \mathrm{mol}$ at starting point and degraded to $26 \mathrm{~kg} / \mathrm{mol}$ in week 6 . Although the starting $M_{\mathrm{w}}$ of mesh1.2 was larger than that of mesh1.5, mesh1.2 had a smaller $M_{\mathrm{w}}$ after 6 weeks of degradation, indicating that fiber with smaller diameter having less mass content and higher surface to volume ratio showed faster degradation in terms of resulting in lower molecular weight.

During degradation, long-chain polymer molecules would be degraded into smaller chains and released into the degradation medium. The mass loss percentage measuring the amount of polymer lost by degradation is commonly used as an indicator of the degradation progress of a biomaterial, which aimed at complete degradation in vivo. The dry mass of the specimens was measured before and after the degradation process at indicated time points. As shown in Fig. 3b, the dry mass of mesh 1.2 decreased to $96.0 \pm 1.5 \%$ in 2 weeks, and further decreased to $88.8 \pm 4.7 \%$ of original after 6 weeks, which was the most significant one among the three groups. While the dry mass of mesh 1.5 and film only decreased to $94.2 \pm 0.3 \%$ and $96.0 \pm 0.4 \%$, respectively, after 6-week incubation in PBS. In comparison, the PDC meshes reported previously, which had an average diameter 
Fig. 2 SEM images of surface morphology of specimens during the hydrolytic degradation over time. Yellow arrows indicate the degraded ends

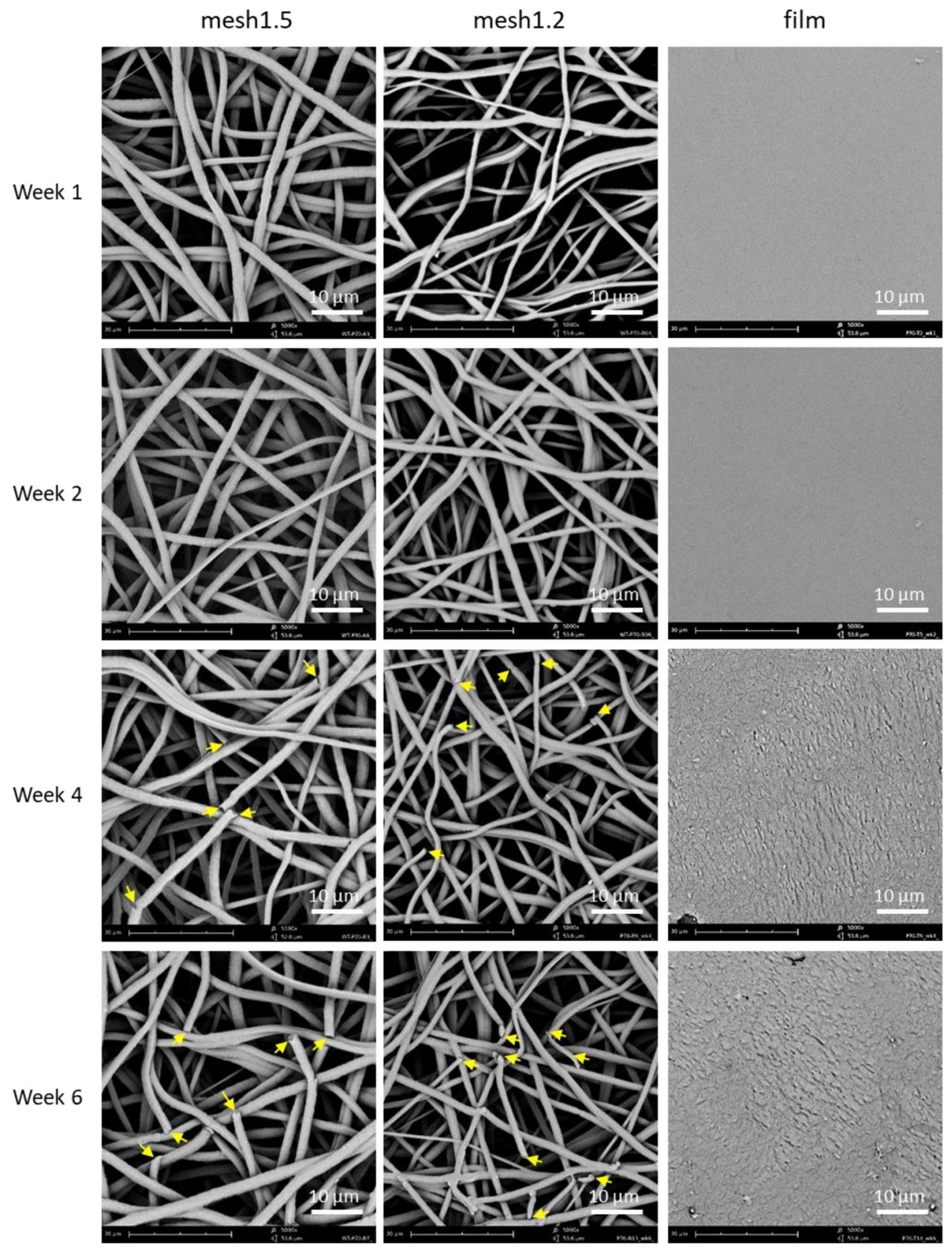

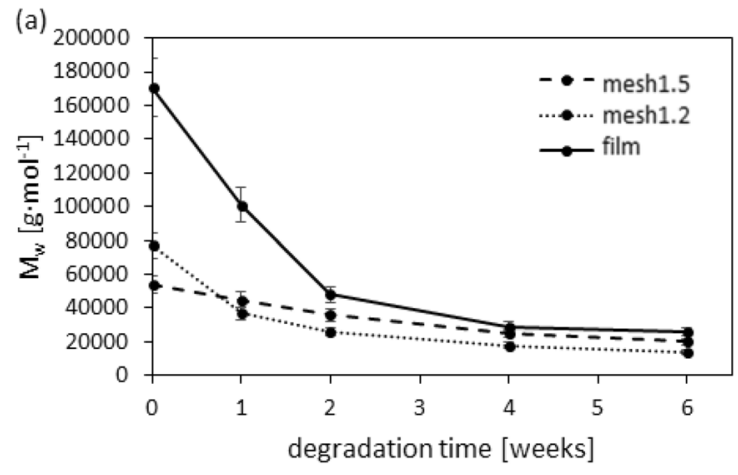

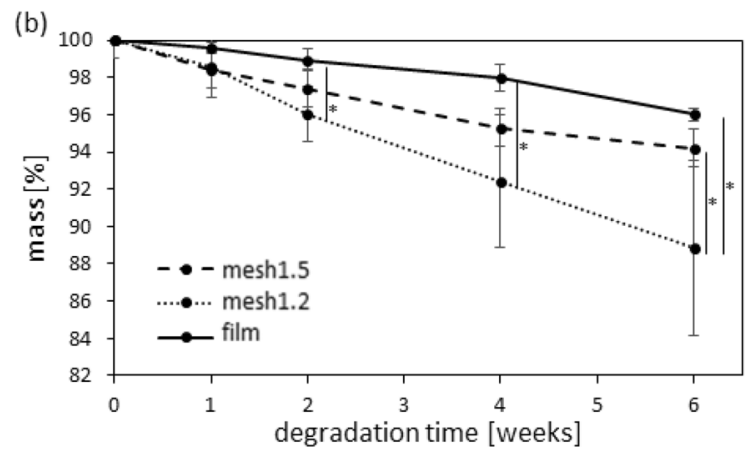

Fig. 3 Measurement of mass and molecular weight during hydrolytic degradation in PBS (pH 7.4). a $M_{\mathrm{w}}$ of samples during 6-week degradation using universal calibration. b Dry mass of samples during 6-week degradation period. $n=4,{ }^{*} p<0.05$

\section{(1) Springer}


of $3 \mu \mathrm{m}$ with a PPDO:PCL ratio of 50:50, showed mass loss around 1.3\% in week 2 and 3\% in week 6 [11]. Our study with smaller fiber diameters and higher amounts of PPDO showed faster degradation in terms of mass loss.

The mechanical properties determined in tensile tests can provide more insight into the degradation behavior of the material and the structural performance during degradation. The tensile test measurements were performed in a thermochamber at $37^{\circ} \mathrm{C}$. From the SEM images (Fig. 2), cracks on fibers perpendicular to fiber axis could be observed from week 4 onwards; therefore, it is expected that the structural function would be lost from week 4 onwards.

The elastic modulus of mesh 1.5 was originally $7.15 \pm$ $0.59 \mathrm{MPa}$ and increased gradually over the degradation time to $11.24 \pm 4.70 \mathrm{MPa}$ and became stiffer in week 6 (Fig. 4a). While the mesh1.2 started with an elastic modulus of $3.26 \pm$ $0.57 \mathrm{MPa}$ and ended at $2.2 \pm 0.42 \mathrm{MPa}$ in week 4 (Fig. 4a), samples in week 6 were cracked after air-dried and no valid measurement could be done. Since the film specimens consist of a bulk structure instead of non-interconnecting fibers with space in between, the elastic modulus was higher than the one of the fiber mesh samples. The film had an elastic modulus of $123.31 \pm 4.50 \mathrm{MPa}$ in the beginning of degradation and increased to $150.90 \pm 6.74 \mathrm{MPa}$ in week 6 (Fig. 4a), showing similar trend to the mesh 1.5 as getting stiffer during the degradation.

While the elastic modulus of the tested specimens increased over the degradation, their elongation at break decreased significantly over the time. The elongation at break of mesh 1.5 decreased from $335 \pm 49 \%$ to $9 \pm 1 \%$ in week 4 while mesh 1.2 decreased from $354 \pm 73 \%$ to 12 $\pm 2 \%$ in week 2 (Fig. $4 \mathrm{~b}$ ). For the film, the elongation at break decreased from $522 \pm 54 \%$ to $18 \pm 11 \%$ in week 4 (Fig. 4b). The previously reported PDC meshes with fibers of larger diameter $(3 \mu \mathrm{m})$ showed slower reduction of elongation at break in hydrolytic degradation, from $800 \%$ to around $500 \%$ in week 2, 200\% in week 4, and $100 \%$ in week 6 [11]. The maximum stress of the fiber meshes and films also had a decreasing trend (Fig. 4c). Mesh1.5 had a maximum stress of $2.83 \pm 0.42 \mathrm{MPa}$ at the starting of degradation and decreased to $0.61 \pm 0.16 \mathrm{MPa}$ in week 4 while that of mesh 1.2 decreased from $1.64 \pm 0.38 \mathrm{MPa}$ to $0.52 \pm 0.06 \mathrm{MPa}$ in week 2 . In comparison, the film had a higher maximum stress allowance.

Based on the aforementioned analysis, the mechanical functionality of mesh 1.5 altered from week 4 on, while that of mesh1.2 from week 2. Both sample groups lost around $5 \%$ of total mass at the respective time point. This implies that the degradation with $5 \%$ of total mass loss determined the structural functionality of the fibers. There will be no sufficient mechanical support provided from the PEEU70 mesh at such a degradation level. In addition, the $M_{\mathrm{w}}$ of mesh 1.5 decreased from $36 \mathrm{~kg} / \mathrm{mol}$ in week 2 to 25 $\mathrm{kg} / \mathrm{mol}$ in week 4 , while that of mesh1.2 decreased from $37 \mathrm{~kg} / \mathrm{mol}$ in week 1 to $26 \mathrm{~kg} / \mathrm{mol}$ in week $2 . M_{\mathrm{w}}$ of the film decreased from $48 \mathrm{~kg} / \mathrm{mol}$ in week 2 to $29 \mathrm{~kg} / \mathrm{mol}$ in week 4 . This could imply that the functional molecular weight, above which the material is still able to show the required mechanical performance [4], is around $30 \mathrm{~kg} / \mathrm{mol}$ in polymer specimen of PEEU70.

Degradation products need to be considered in the context of the biological response besides development of structural performance over time. Since both PPDO and PCL contain one ester group per repeating unit, the chain scission process in hydrolytic degradation cleaves the esters into small molecules with one hydroxy endgroup and a terminal carboxy group. The products could be seen by cells as metabolites similar to fatty acids and undergo fatty acid oxidation (FAO). One important key player in regeneration process is macrophages, which can change their own phenotype towards pro-inflammatory or anti-inflammatory. A recent study showed that apoptotic cell fatty acid supplied to macrophage for FAO could escalate the production of interleukin-10 (IL-10) which could promote the anti-inflammatory macrophage phenotype [18]. The prolonged degradation time over mechanically functional time might turn PEEU material into fatty acid delivery material enabling on site promotion of anti-inflammatory macrophage phenotype.
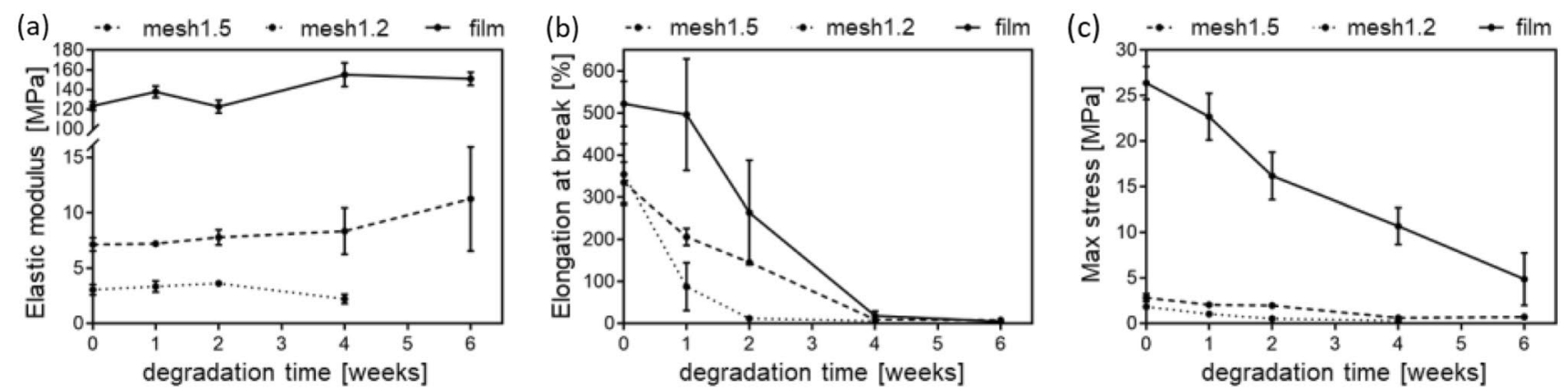

Fig. 4 Changes in mechanical properties at $37{ }^{\circ} \mathrm{C}$ of hydrolytically partially degraded PEEU. a Elastic modulus, b elongation at break, and c maximum stress of specimens over time during degradation. $n \geq 4$ 
Investigation in tracking degradation product released to surrounding would be of interest in a future study.

\section{Conclusion}

This study provides an insight into the degradation behavior of sterilized PEEU70 material specimen. Different shapes of material specimen were tested for hydrolytic degradation and characterized by mass loss, surface morphology, structural functionality, and molecular weight. Fiber meshes with average fiber diameter of $1.2 \mu \mathrm{m}$ resulted in faster degradation compared to other samples and loss of structural functionality appeared in week 2 due to the faster water uptake into the polymeric fiber structure for bulk degradation. While meshes with an average fiber diameter of $1.5 \mu \mathrm{m}$ and films showed functionality during the degradation till week 4. A drop in $\mathrm{M}_{\mathrm{w}}$ below $30 \mathrm{~kg} / \mathrm{mol}$ was considered to be critical in terms of mechanical stability, as the elongation at break of the samples reached values below $20 \%$.

Acknowledgements $\mathrm{M}$. Zierke is acknowledged for material synthesis and O. Lettau for assistance with GPC measurement. This work was financially supported by the Helmholtz Association of German Research Centers through programme-oriented funding and through Helmholtz Graduate School of Macromolecular Bioscience (MacroBio, VH-GS-503).

Funding Open Access funding enabled and organized by Projekt DEAL.

Data availability Data will be made available on reasonable request.

\section{Compliance with ethical standards}

Conflict of interest The authors declare that they have no conflicts of interest.

Open Access This article is licensed under a Creative Commons Attribution 4.0 International License, which permits use, sharing, adaptation, distribution and reproduction in any medium or format, as long as you give appropriate credit to the original author(s) and the source, provide a link to the Creative Commons licence, and indicate if changes were made. The images or other third party material in this article are included in the article's Creative Commons licence, unless indicated otherwise in a credit line to the material. If material is not included in the article's Creative Commons licence and your intended use is not permitted by statutory regulation or exceeds the permitted use, you will need to obtain permission directly from the copyright holder. To view a copy of this licence, visit http://creativecommons.org/licenses/by/4.0/.

\section{References}

1. R. Song, M. Murphy, C. Li, K. Ting, C. Soo, Z. Zheng, Drug Des. Dev. Ther. 12, 3117-3145 (2018)

2. K. Fukushima, M.-Y. Tsai, T. Ota, Y. Haga, K. Matsuzaki, Y. Inoue, M. Tanaka, Polym. J. 47(7), 469-473 (2015)

3. A. Kulkarni, J. Reiche, J. Hartmann, K. Kratz, A. Lendlein, Eur. J. Pharm. Biopharm. 68(1), 46-56 (2008)

4. S. Lyu, D. Untereker, Int. J. Mol. Sci. 10(9), 4033-4065 (2009)

5. W. Cui, X. Li, S. Zhou, J. Weng, Polym. Degrad. Stab. 93(3), 731-738 (2008)

6. X. Sun, W. Tung, W. Wang, X. Xu, J. Zou, O.E.C. Gould, K. Kratz, N. Ma, A. Lendlein, Clin. Hemorheol. Microcircul. 73(1), 219-228 (2019)

7. X. Sun, W. Tung, J. Zou, W. Wang, K. Kratz, N. Ma, A. Lendlein, Clin. Hemorheol. Microcircul. 74, 405-415 (2020)

8. J. Rouwkema, N.C. Rivron, C.A. van Blitterswijk, Trends Biotechnol. 26(8), 434-441 (2008)

9. B. Hiebl, C. Mrowietz, J. Goers, M. Bahramsoltani, J. Plendl, K. Kratz, A. Lendlein, F. Jung, Clin. Hemorheol. Microcircul. 46, 233-238 (2010)

10. T. Haase, R. Klopfleisch, A. Krost, T. Sauter, K. Kratz, J. Peter, F. Jung, A. Lendlein, D. Zohlnhöfer, C. Rüder, Clin. Hemorheol. Microcircul. 75(2), 163-176 (2020)

11. K. Kratz, R. Habermann, T. Becker, K. Richau, A. Lendlein, Int. J. Artif. Org. 34(2), 225-230 (2011)

12. A. Lendlein, R. Langer, Science 296(5573), 1673-1676 (2002)

13. M.A. Sabino, J. Albuerne, A.J. Müller, J. Brisson, R.E. Prud'homme, Biomacromolecules 5(2), 358-370 (2004)

14. B. Hiebl, R. Fuhrmann, F. Jung, K. Kratz, A. Lendlein, R.P. Franke, Clin. Hemorheol. Microcircul. 45(2-4), 117-122 (2010)

15. J. Reiche, A. Kulkarni, K. Kratz, A. Lendlein, Thin Solid Films 516(24), 8821-8828 (2008)

16. X. Lin, Y. Liu, A. Bai, H. Cai, Y. Bai, W. Jiang, H. Yang, X. Wang, L. Yang, N. Sun, H. Gao, Nat. Biomed. Eng. 3(8), 632-643 (2019)

17. M. Richard-Lacroix, C. Pellerin, Macromolecules 46(24), 9473 $9493(2013)$

18. S. Zhang, S. Weinberg, M. DeBerge, A. Gainullina, M. Schipma, J.M. Kinchen, I. Ben-Sahra, D.R. Gius, L. Yvan-Charvet, N.S. Chandel, P.T. Schumacker, E.B. Thorp, Cell Metab 29(2), 443456.e445 (2019) 